\title{
Modeling of the Automatic Mechanical Injection System
}

\author{
Louiz Akram \\ The Higher Institute for Maritime Studies, Morocco-Naval Engineering, Morocco \\ Received October 8, 2019; Revised November 22, 2019; Accepted November 28, 2019
}

Copyright $\bigcirc 2019$ by authors, all rights reserved. Authors agree that this article remains permanently open access under the terms of the Creative Commons Attribution License 4.0 International License

\begin{abstract}
In many industrial fields, there is an ever growing market demand for highly profitable engines. This fact encouraged to produce very developed engine parts, namely sophisticated injection systems. Consequently, the electronically enhanced injection systems are becoming very widespread for their high efficiency and cause the mechanical automatic systems to be neglected without enough studies. However, the electronically commanded injection is difficult to maintain because of the risks of short-circuits, and it is also difficult and expensive to repair since its captors are in high pressure and temperature areas. This paper aims to introduce a mathematical study of the basic direct injection operation by proving formulas representing forces, velocities and the energy involved in the injection mechanical mechanism without any electronic or computational complications. This theoretical mathematical modeling is useful for the efficiency experimental studies in order to improve the manufacturing and maintenance of all direct injection systems.
\end{abstract}

Keywords Injection System, Mechanical Engine, Internal Combustion, Motors, Heat Engines, Injection Pump, Injector, Energetic Efficiency, Modeling, Nozzle, Plunger, Injection Mechanism, Flame, Fuel, Injection Process, Direct Injection

\section{Introduction}

The internal combustion motors are still conventional worldwide for the energy production. Consequently, thousands of institutes around the world are still competing to add the best improvements to these engines in order to enhance their energetic efficiency and reduce their pollutant emissions.

The direct injection motors are heat engines which use the fuel to produce the mechanical energy. The fuel is directly injected by an injection system that is mainly compound of an injection pump and an injector. The first consumes a part of the engine mechanical energy through the camshaft to raise the pressure of the fuel inside the second. This operation allows the spraying of the fuel in the cylinder through the injector. Hence, the combustion of the fuel occurs in the cylinder and makes the piston transform the heat to a mechanical useful energy. This obviously means that the energetic efficiency of the engine depends directly on the efficiency of the injection system. This fact encourages many researchers to study this system and propose solutions that enhance its efficiency. However, most of them propose high intelligence electronic parts to impose an injection rate profile while dealing with the velocity/mass flow rate as a function of time before proposing a new injection modeling.

The injection rate profile can be rectangular, triangular, ramp or boot and optimizing it controls the combustion process by improving the trade-off of nitrogen oxides fuel consumption and emission [1]. However, it is a complex operation that isn't applied widely yet in the common direct injection engines since it requires additional expensive computing and electronic parts.

The formulas of the modeling are presented in this paper within a new personal approach according to the simplified injection system parts illustrated below in order to introduce all kinds of interested readers to the wide topic of the direct injection researches.

This paper is structured as follows:

The background and literature review is the part that exposes the history and the general information about the injection. Furthermore, many important related works are cited and referenced with their corresponding explanations since they are very useful to non-experts, whereas the proposed approach comes next to explain and prove the formulas of this topic. At the end, a related work has been used to verify and validate experimentally the results and remarks made in this paper before the last part that summarizes the work and reminds the main conclusions.

\section{Background and Literature Review}

\subsection{Background}

Fuel injection systems were well-known long before the 
First World War. They have been recorded since the beginning of the twentieth century in many engine inventions even if carburetors were used in aircraft engines before the First World War.

Injection carburetors are lighter and simpler than fuel injection systems and were used by different Companies to develop different other designs and solutions like the manifold injection.

The nozzle of the direct fuel injection sprays fuel into the combustion chamber in the cylinder where the compressed air reaches a high temperature before the ignition makes the fuel evaporate. Whereas the air mixed with the fuel enters the combustion chamber at some point between the supercharger inlet and the individual cylinder intake valve in other injection inventions.

Injection technologies were at their beginnings completely mechanical, but a first successful electronic system has been made by Bosh and appeared on the 1967 Volkswagen 1600. It uses sensors that are mounted at different parts of the engine, a computer and solenoid operated fuel injector. An electronic control unit receives information in the form of electronic signals from the sensors to regulate the rate profile and the amount of fuel injected into the cylinders.

The obvious principles of these injection systems are explained in many descriptive documents such as books of marine diesel engines [2], but that only descriptive literature makes of the reader a future low grade technician.

Engine technicians should still improve their skills in such an ever-evolving field because they should understand how useful is each design of the injection systems. Low grade engine technicians can't make use of new improved injection systems or at least repair an old system by using recently improved spare parts, and they can't make use of the new researches about the injection systems as engineers.

Hence, I am presenting this paper to all grades of engine technicians and engineers, and also to the interested readers of different fields of study since the prerequisites are only the information they gathered about their cars engines and some simple geometry. For instance, the curved surface area of a cone is: $\pi \mathrm{Lr}$, where $\mathrm{L}$ stands for the slant height of the cone and $r$ stands for the radius of the base of the cone. The symmetry of the cone causes that the resulting force upon its surface by a pressure causes a resulting force along the axis and the same thing happens with a spherical cap surface.

This paper allows the reader to link theoretically all the injection process steps together and enables to understand better the forces and energies involved in other researches that describe and model the injection spray pattern.

The spray development starts by the primary break-up stage, the secondary break-up stage and then the evaporation that allows the combustion and sometimes the impingement on the piston head and the cylinder walls
[3].

Most of the other works use the Computational fluid dynamics (CFD) that is a branch of fluid mechanics for the modeling by using numerical analysis and data structures assisted by a computer in order to analyze and solve the injection modeling problems $[4,5,6]$.

This work can therefore be a basis to discover the other related topics especially the electronic injection systems that use electronic control units (ECU) to enhance the engine performance [7].

\subsection{The Direct Injection System}

The injection system is a fundamental part of the direct injection engine that uses the internal combustion to produce the mechanical energy. During the combustion, the fuel is directly injected in the combustion chamber in order to provide the heat supply that is transformed to a mechanical energy through the connecting rod and crank system.

The direct injection systems can be purely mechanical but high intelligence electronic systems are being developed recently in order to reach a high precision injection. The injection electronic systems use the computing intelligence to make the combustion flame completely controlled and thus to enhance the engine efficiency. However, the mechanical automatic injection allows us to make engines independent from the electric energy and easy to repair. It is also a cheaper injection system with an easy maintenance and can also make the engine reach a high efficiency.

Most of the injection systems use a helical spring and needle as a valve mechanism to spray the fuel in the combustion chamber by counting on the pressure of a pump. It is a process made of five stages:

1. The fast opening of the injector valve.

2. The slow compression of the helical spring.

3. The stage where the valve is fully open.

4. The slow depression of the helical spring.

5. The fast closing of the injector valve.

However, when the injection duration is short, the second and fourth stage can be neglected by considering only one long stage where the injector valve is fully open [8].

During the experiments of direct injection systems, it is easy to measure v' the total injected fuel volume per cycle for a cylinder but it is difficult to find their injection rate profiles. Consequently, for the following modeling, the considered case is the common one where there are steady-state flow conditions where the fuel is continuously injected in the same manner and produces a continuous spray, thanks to the engine camshaft. In the proposed efficiency formulas, the combustion of the fuel is also considered complete without taking into account the process efficiency of the thermal energy transformation into mechanical energy. 


\subsection{Related Works}

The design parameters of the injection system parts are obviously important for the optimum combustion. However, the injection parts used to develop this modeling are only very simplified ones that can be easily manufactured by choosing freely the number and parameters of the nozzle identical holes in order to investigate experimentally more different characteristics.

For example, C. Arcoumanis, M. Gavaises and J. M. Nouri collaborated with members of Ford company [9] and used an injector of six nearly similar holes with steady-state flow conditions to investigate experimentally the effect of the manufacturing slight difference between the injector holes sizes. They also studied experimentally the cavitation and the flow distribution within the injector main parts by changing the holes inclination angle and there entrance curvature radius. They also investigated, by changing the eccentricity and the lift of the needle, the effects on the flow and the pressure at the injector main parts. However, they concluded that the flow rate remains practically constant for needle lifts higher than $2 \mathrm{~mm}$.

Their experiments also tried to validate the computational fluid dynamics (CFD) model for the flow distribution of the fuel, and the same is done in many other experimental works, namely the work of A. J. Yule and I. Filipovic [10] that validates experimentally the CFD sub-models of the break-up zone and describes the break-up time. However, the initial penetration velocity has been calculated differently by using suitable Weber and Reynolds numbers that are not used in this work.

A different work completes my paper by introducing a new spray model. It is a work realized by Mark A. Patterson and Rolf D. Reitz [11] that uses the Rayleigh-Taylor type instabilities and the Kelvin-Helmholtz waves in order to model the fuel Spray characteristics. It is a very important work that predicts the amount of pollutant emissions for each kind of injection. Furthermore, it can also allow the design of a better engine piston head for each injection system especially if we take into consideration the good model of the spray wall impingement.

A modeling of the spray wall impingement processes has been made by Z Han, Z Xu and N Trigui [12]. They used in their work linear instability analysis and statistics in order to describe the wave phenomena of the injected fuel. They also took images from inside the combustion chamber and validated the CFD sub-models. Whereas more accurate ultra-high speed imaging illustrates the spray pattern and its impingement on the piston head and the cylinder walls in a recent different experimental work made by Ziman Wang, Haichun Ding, Xiao Ma, Hongming Xu and Miroslaw L. Wyszynski [13].

\section{Proposed Approach}

We consider a direct injection system simplified as in the following figures:

Figure 1 illustrates the nozzle of diameter $\mathrm{d}$ and the injector needle of diameter D pushed downwards by a helical spring compressed within a length $\Delta \mathrm{x}$. The spring is of a stiffness $\mathrm{k}$ and a setting length $\Delta \mathrm{x}$, and $\theta$ is the angle of the needle slant surface. In this case, the position of the needle does not allow the injection when the fuel pressure $P_{l}$ is not enough.

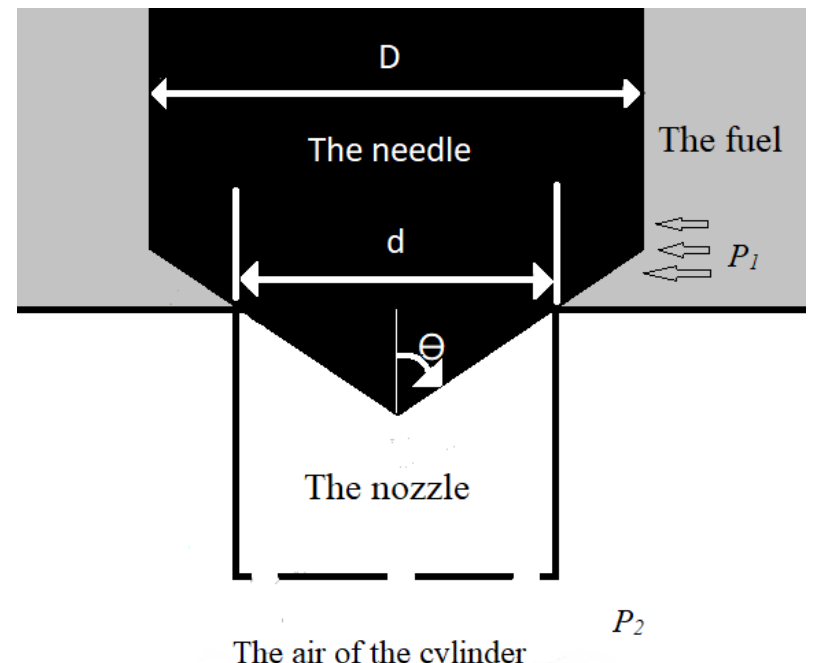

Figure 1. The injector needle and nozzle before the injection

Figure 2 illustrates the nozzle and the injector needle in a position where the fuel pressure $P_{l}$ is enough to compress the spring and allow the injection. During the injection, $V_{1}$ is the speed of the fuel in the nozzle (point 1) and $\mathrm{V}_{2}$ is the fuel velocity at the $\mathrm{N}$ identical holes of the injector (point 2). The air necessary for the combustion has a pressure $\mathrm{P}_{2}$ in the cylinder.

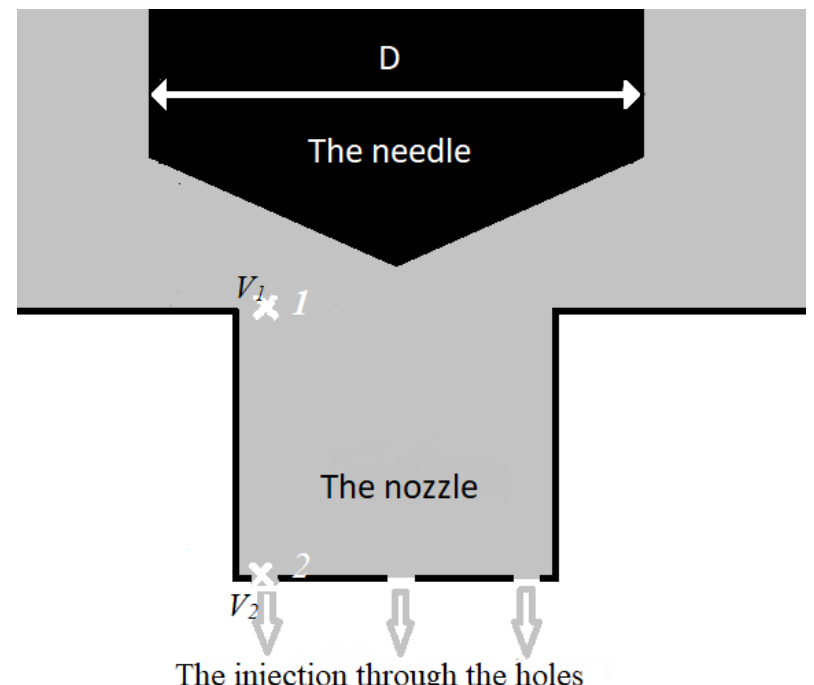

Figure 2. The injector needle and nozzle during the injection

Figure 3 illustrates the surface $S$ of the injection pump plunger head and its velocity $\mathrm{V}$ along the height $\mathrm{h}$. The 
pressure $P_{1}$ is caused by a mechanical force upon the plunger.

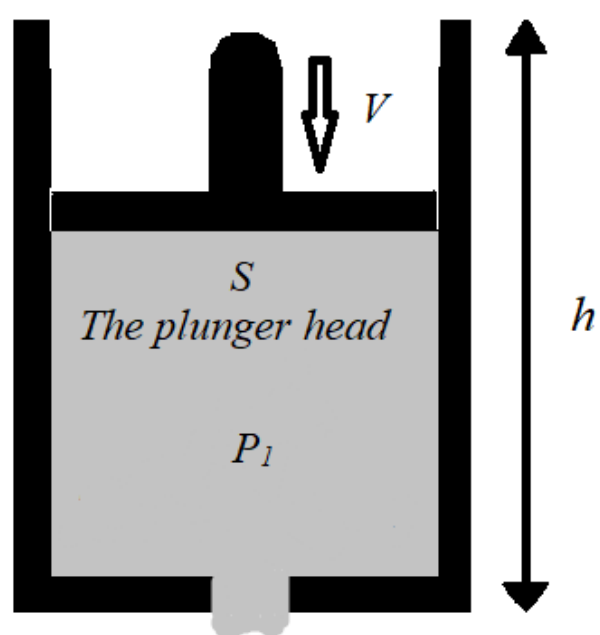

\section{To the injector}

Figure 3. A simplified injection pump

Figure 4 illustrates the mechanism of the fuel overflow valve that is a safety relief valve. It uses a steel ball instead of the needle to prevent the fuel to flow upwards. A piston of diameter D' pushes the steel ball downwards thanks to the force of a spring in order to close the entry of diameter d'.

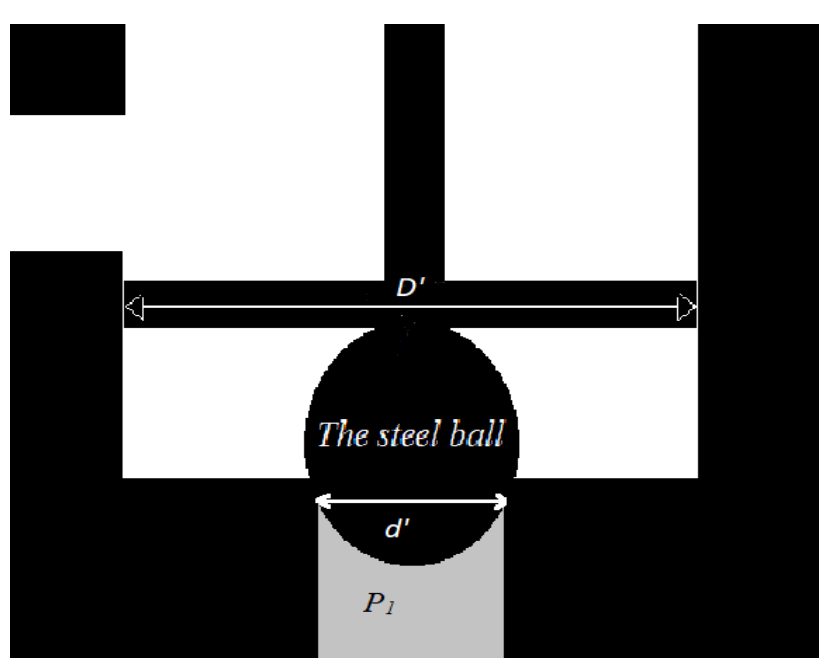

Figure 4. The steel ball and the piston of the fuel overflow valve before it is activated

Figure 5 illustrates $\left(\mathrm{G}^{\prime \prime}\right) \rightarrow$ the force upon the steel ball slant by the angle $\theta$ and caused by the pressure $P_{l}$. The distance 1 and the direction of $\left(\mathrm{G}^{\prime \prime}\right) \rightarrow$ change by $\theta$, but the strength of $G$ ', is the same on all the points exposed to the fuel pressure $P_{l}$.

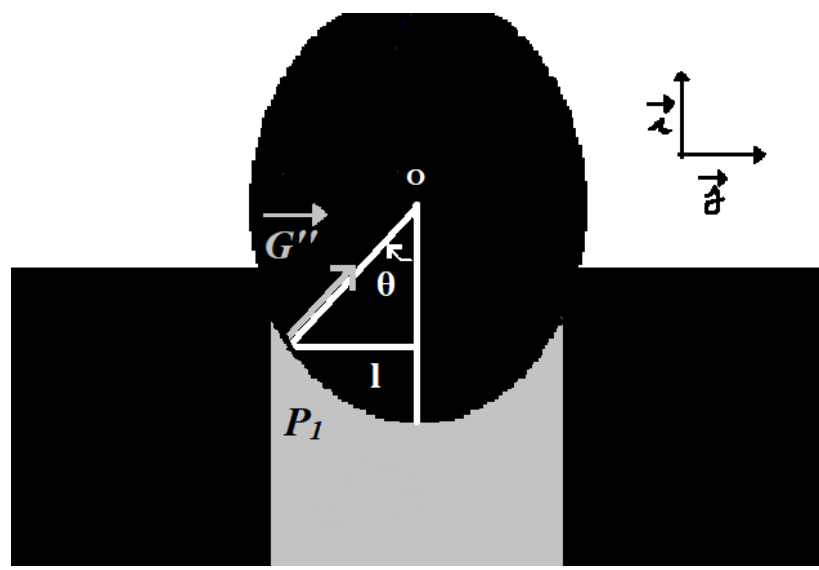

Figure 5. The force by the pressure $P_{1}$ and its direction

Figure 6 illustrates the piston of the fuel overflow valve and the steel ball of radius $\mathrm{R}$ in a position that allows the evacuation of the fuel for the relief of the injector. When the fuel pressure P' is too high to the injection mechanism, this valve is activated by the compression of its spring.

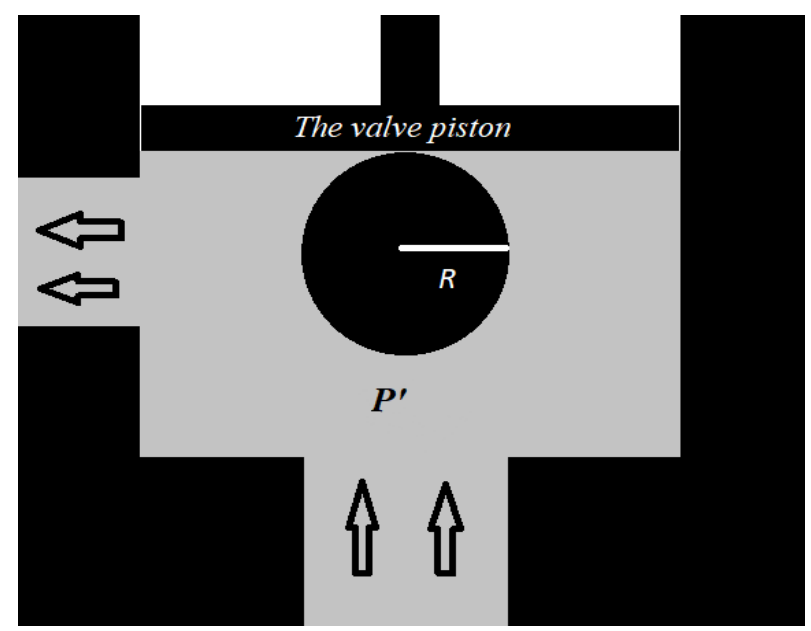

Figure 6. The steel ball and the piston of the fuel overflow valve when it is activated

Figure 7 illustrates the main parts of the injection system and explains the flow of the fuel during the injection process where there is an overpressure that activates the fuel overflow valve. The injection pump gets a mechanical energy from the engine through the camshaft in order to rise the fuel pressure in the injector. 


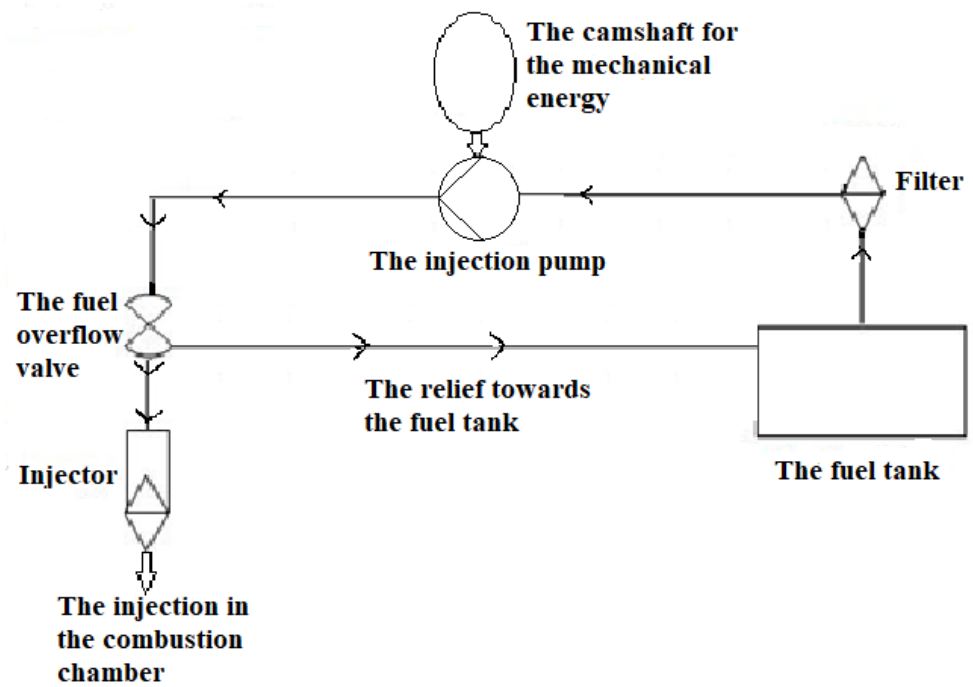

Figure 7. A schematic diagram of the fuel injection system

Application: We consider, before the start of the injection, that $\overrightarrow{\mathrm{F}}$ ', is the force on the surface $\mathrm{S}$ ' by the pressure $P_{l}$. S' is the surface slant by the angle $\theta$ exposed to the pressure $P_{l}$.

The surface $S^{\prime}$ is slant, we deduce then:

$$
F^{\prime}=F^{\prime \prime} \times \sin \theta
$$

$\vec{F}$ ' is the resulting effective force on the needle by the pressure $P_{l}$ before the start of the injection, because $\vec{F}$, is perpendicular upwards thanks to the symmetry of the needle,

Consequently:

$$
F^{\prime}=P_{1} \times S^{\prime} \times \sin \theta
$$

And thanks to the surfaces of cones, we deduce that:

$$
S^{\prime}=\frac{\pi}{4 \times \sin \theta} \times\left(D^{2}-d^{2}\right)
$$

Consequently:

$$
F^{\prime}=\frac{\pi}{4} \times\left(D^{2}-d^{2}\right) \times P_{1}
$$

$F^{\prime}$ increases when the injection pump plunger is pushed by a mechanical force from the engine. However, when that mechanical force is strong enough, F' slightly exceeds the spring force $\mathrm{k} \times \Delta \mathrm{x}$ and thus the injection starts.

Hence, $\mathrm{P}_{1}$ slightly exceeds the value: $\frac{4 \times k \times \Delta x}{\pi \times\left(D^{2}-d^{2}\right)}$ by the small value $\mathrm{dP}$, which means:

$$
P_{1}=\frac{4 \times k \times \Delta x}{\pi \times\left(D^{2}-d^{2}\right)}+d P
$$

where $\mathrm{dP}$ is negligible.

The consumed energy to reach $F^{\prime}$ in order to activate the injector is:

$$
E_{1} \approx \frac{1}{2} \times k \times(\Delta x)^{2}
$$

We proved the threshold pressure for the start of the injection. It depends on the setting length $\Delta \mathrm{x}$ and on the diameters $d$ of the nozzle and $\mathrm{D}$ of the needle. However, the consumed injector activation energy depends exclusively on the spring.

When the threshold pressure is surpassed, the volume taken by the fuel inside the injector increases instantaneously, which causes a short delay of the injection start.

The normal pressure case (ideal case): At the start of the injection, the spring of the injector is instantaneously compressed by the length $\mathrm{dx}$ so the fuel pressure reaches the entire cone of the needle instead of only the surface $S$ '.

This happens because the fuel is incompressible and the injection system parts don't dilate but the fuel is continuously pushed by the injection pump plunger.

Consequently, F' changes and respects this equation:

$$
\mathrm{F}^{\prime}=\frac{\pi}{4} \times D^{2} \times P_{1}=k \times(\Delta x+d x)
$$

Hence, we conclude that:

$$
P_{1}=\frac{4 \times k \times(\Delta x+d x)}{\pi \times D^{2}}
$$

Also, the fuel flow rate through the injector is maximal since the beginning of the injection and thus $P_{l}$ is maximal and stable. Consequently, by considering the injection made in a short duration, $\mathrm{dx}$ is also maximal since the beginning of the injection.

As the injector gets older, we should increase the setting length $\Delta \mathrm{x}$ because of the natural decrease of the spring stiffness $k$. This operation allows us to produce the same pressure $\mathrm{P}_{1}$ mandatory for the engine normal injection.

We consider that $\Delta \mathrm{x}+\mathrm{dx}=\mathrm{L}$ where $\mathrm{L}$ is the maximal compression length of the injector spring for a determined $\Delta \mathrm{x}$.

We can also conclude that the increase of force necessary to find the equilibrium of the forces is:

$$
d f=\frac{\pi}{4} \times d^{2} \times P_{1}=k \times d x
$$

and thus: 


$$
P_{1}=\frac{4 \times k \times d x}{\pi \times d^{2}}
$$

Hence we have this equation:

$$
\frac{d x}{d^{2}} \approx \frac{\Delta x+d x}{D^{2}}
$$

Consequently:

$$
d x \approx \frac{\Delta x \times d^{2}}{D^{2}-d^{2}}
$$

so:

$$
L \approx \Delta x \times \frac{D^{2}}{D^{2}-d^{2}} \text { where: } \Delta \mathrm{x}+\mathrm{dx}=\mathrm{L}
$$

We increase $\Delta \mathrm{x}$ of an injector by increasing the useful (compressible) part of the injector spring. Consequently, we can expect using this formula the length $\mathrm{L}$ corresponding to each $\Delta \mathrm{x}$ for a determined injector.

We can also conclude the force upon the injection pump plunger (by the engine camshaft):

$$
\mathrm{F}=\mathrm{P}_{1} \times \mathrm{S}=\frac{4 \times \mathrm{k} \times \mathrm{L}}{\pi \times \mathrm{D}^{2}} \times \mathrm{S} \approx \frac{4 \times \mathrm{k} \times \Delta \mathrm{x}}{\pi \times\left(\mathrm{D}^{2}-\mathrm{d}^{2}\right)} \times \mathrm{S}
$$

The energy consumed by each injection pump during an injection of short duration is:

$$
\mathrm{E}_{2}=\mathrm{F} \times \mathrm{h}=\mathrm{P}_{1} \times \mathrm{v}^{\prime} \approx \frac{4 \times \mathrm{k} \times \Delta \mathrm{x}}{\pi \times\left(\mathrm{D}^{2}-\mathrm{d}^{2}\right)} \times \mathrm{v}^{\prime}
$$

where $\mathrm{h}$ is the height of the injection pump cylinder and $\mathrm{v}$ ' the total volume of the injected fuel. The volume v' is the volume of the injection pump cylinder that can also be changed by the user. We can change it by using the fuel rack in order to change the engine's speed.

By considering, during a short injection that the combustion is complete at the engine's cylinder, we can find the efficiency $\mathrm{e}_{\mathrm{ff}}$ of each injection pump as follows:

$$
\mathrm{e}_{\mathrm{ff}}=\frac{\mathrm{C}_{\mathrm{a}} \times \mathrm{v}^{\prime}}{\mathrm{E}_{1}+\mathrm{E}_{2}} \approx \frac{2}{\mathrm{k} \times \Delta \mathrm{x}} \times \frac{\mathrm{C}_{\mathrm{a}}}{\frac{\Delta \mathrm{x}}{\mathrm{v}}+\frac{8}{\pi \times\left(\mathrm{D}^{2}-\mathrm{d}^{2}\right)}}
$$

Where $\mathrm{C}_{\mathrm{a}}$ is the calorific value of the fuel.

The overpressure case: When the fuel flow rate through the injector is insufficient, the pressure becomes instantaneously too high and dangerous for the injection mechanism, and thus the fuel overflow valve is activated by the compression of its helical spring.

We consider, before the activation of the fuel overflow valve, that $\vec{G}^{\prime \prime}$ is the force applied upon the smallest part dS of the surface $S$ ' ' by the pressure $P_{1} . S$ ', is the spherical cap surface of the steel ball exposed to the pressure $P_{1}$ and thus:

$$
G^{\prime \prime}=P_{1} \times d S
$$

by considering that $\mathrm{dS}$ is the elementary surface of a sphere, consequently:

$$
d S=R^{2} \times \sin (\theta) \times d \theta \times d \varphi
$$

The surface $S$ ', is a spherical cap, we deduce then:

$$
G^{\prime}=G^{\prime \prime} \times \cos \theta
$$

And thus :

$$
G^{\prime}=P_{1} \times R^{2} \times \sin (\theta) \times \cos (\theta) \times d \theta \times d \varphi
$$

Where $\vec{G}$, is the pressure effective force on the part $\mathrm{dS}$ of the surface $S$ ' by the pressure $\mathrm{P}_{1}$ before the start of the injection, since $\vec{G}$, is the perpendicular component of $\vec{G}^{\prime \prime}$ upwards along the axis $\vec{I}$.

This is caused by the fact that each $\vec{G}^{\prime \prime}$ component along $\vec{J}$ has an opposed other $\vec{G}^{\prime \prime}$ component along $\vec{J}$ that deletes it thanks to the symmetry of the surface S".

We start by finding $H^{\prime \prime}$ the resulting pressure force on the steel ball circle where $\vec{G}$, is the same, it is the circle with a fixed angle $\theta$ :

$$
H^{\prime \prime}=2 \pi \times l \times P_{1} \times R^{2} \times \sin (\theta) \times \cos (\theta) \times d \theta
$$

We have:

$$
l=R \times \sin \theta
$$

Consequently:

$$
H^{\prime \prime}=2 \pi \times P_{1} \times R^{3} \times \sin (\theta)^{2} \times \cos (\theta) \times d \theta
$$

We should integrate $H^{\prime}$ ' from 0 to $\theta_{\max }$ to find $\mathrm{H}^{\prime}$ the resulting pressure force on the entire surface $S$ ', exposed to the fuel pressure before the activation of the fuel overflow valve.

We conclude that:

$$
\begin{gathered}
H^{\prime}=\int_{0}^{\theta_{\max }} H^{\prime \prime}=2 \pi \times P_{1} \times R^{3} \times \int_{0}^{\theta_{\max }} \sin (\theta)^{2} \times \\
\cos (\theta) \times d \theta
\end{gathered}
$$

Hence :

$$
\begin{gathered}
H^{\prime}=2 \pi \times P_{1} \times R^{3} \times \frac{\sin \left(\theta_{\max }\right)^{3}}{3} \text { where: } \theta_{\max }= \\
\arcsin \frac{d \prime}{2 R}
\end{gathered}
$$

Consequently:

$$
H^{\prime}=\frac{\pi}{12} \times P_{1} \times d^{\prime 3}
$$

When the maximum pressure $\mathrm{P}_{1}$ allowed by the setting length $\Delta x$ is exceeded to a dangerous higher pressure $\mathrm{P}^{\prime}$, $\mathrm{H}^{\prime}$ slightly exceeds the spring force $k^{\prime} \times \Delta x^{\prime}$ and thus:

$$
P^{\prime}=12 \times \frac{k \prime \times \Delta x \prime}{\pi \times d^{\prime 3}}+d P
$$

Where $\mathrm{dP}$ is negligible.

The fuel overflow valve will be consequently activated and the consumed energy for that operation is:

$$
E_{3} \approx \frac{1}{2} \times k^{\prime} \times\left(\Delta x^{\prime}\right)^{2}
$$

We proved the threshold pressure for the activation of the fuel overflow valve. It depends on the length $\Delta x^{\prime}$ and on the diameter d' of the valve entry but not on $\mathrm{R}$ the steel ball radius. However, the consumed activation energy depends exclusively on the valve spring.

We also note that $E_{2}$ changes to a higher energy $E_{4}$ where:

$$
E_{4}=P^{\prime} \times v^{\prime}
$$

since $P^{\prime}>P_{1}$.

And since after the rise of the steel ball by a length $d x$ ' we get: 


$$
\pi \times \text { Where: } \Delta x^{\prime}+d x^{\prime}=L^{\prime}
$$

because the surface above the steel ball gets totally pushed by the fuel pressure.

By considering the same thermodynamic principles of the normal pressure case, we conclude that:

$$
P^{\prime}=\frac{4 \times k \prime \times L^{\prime}}{\pi \times}
$$

L' is the maximal spring compression length in the fuel overflow valve for a determined $\Delta x^{\prime}$ and that allows the maximal relief and safety of the valve. Hence, we have this equation:

$$
\frac{4 \times k \prime \times L \prime}{\pi \times D^{\prime 2}} \approx 12 \times \frac{k \prime \times \Delta x \prime}{\pi \times d^{\prime}}
$$

Consequently:

$$
d x^{\prime} \approx \frac{3 \times \Delta x{ }^{\prime} \times D^{\prime}}{d^{3}}-\Delta x^{\prime}=\Delta x^{\prime} \times\left(\frac{3 D^{\prime 2}}{d^{\prime 3}}-1\right)
$$

And thus:

$$
L^{\prime} \approx 3 \times \Delta x^{\prime} \times \frac{D \prime^{2}}{d^{\prime 3}}
$$

Consequently:

$$
E_{4}=\frac{4 \times k \prime \times L^{\prime}}{\pi \times D^{\prime 2}} \times v^{\prime}=\frac{12 \times k \prime \times \Delta x \prime}{\pi \times d^{3}} \times v^{\prime}
$$

The volume $\mathrm{v}^{\prime}$ is the volume of the injection pump cylinder since we consider that the fuel overflow valve is activated since the beginning of the injection.

Hence, during a short injection duration, by considering, that the combustion is complete at the engine's cylinder, the efficiency $e_{f f}$ changes to $e_{f f}^{\prime}$ :

$$
e_{f f}^{\prime}=\frac{C_{a} \times v^{\prime}}{E_{1}+E_{3}+E_{4}} \approx \frac{2}{k^{\prime}} \times \frac{C_{a}}{\frac{k}{k \prime} \times \frac{(\Delta x)^{2}}{v \prime}+\frac{(\Delta x)^{2}}{v \prime}+\frac{24 \times \Delta x^{\prime}}{\pi \times d^{\prime}}}
$$

We can also conclude from $P^{\prime}>P_{1}$ that:

$$
\frac{k \prime \times \Delta x \prime}{k \times \Delta x}>\frac{d^{3}}{3 \times\left(D^{2}-d^{2}\right)}
$$

The efficiency $e_{f f}^{\prime}$ is lower than $e_{f f}$ because $E_{3}>0$ and $E_{4}>E_{2}$. This fact implies that the force $\mathrm{F}$ upon the injection pump plunger (by the camshaft) should be rigorously adjusted to reach the pressure $\mathrm{P}$ where: $P_{1} \leq P<P^{\prime}$.

These are the formulas of the consumed forces and energy by the injection mechanism. They will allow us to choose the correct dimensions of the injection system parts and cams and to model the energy consumed by the injector for a better efficiency.

These formulas don't depend on $\mathrm{N}$ the number of the injector holes. However, we note that the injection efficiency increases with the increase of $\mathrm{v}$ ' the injected fuel total size.

We also note that the efficiency always decreases as the injector gets older because of the increasing setting lengths $\Delta x$ and $\Delta x^{\prime}$. This decrease happens even if the stiffnesses $\mathrm{k}$ and k' decrease because the values of $\Delta x$ and $\Delta x^{\prime}$ are squared in the energies formulas $E_{1}, E_{2}$.

The spray development start velocity: During the injection, by considering that the $\mathrm{N}$ injector holes are perfectly identical, we can also use the following equation between the points 1 and 2 :

$$
\begin{gathered}
\alpha_{1} \times \rho \times \frac{\mathrm{V}_{1}^{2}}{2 \times \mathrm{N}^{2}}-\alpha_{2} \times \rho \times \frac{\mathrm{V}_{2}^{2}}{2}+\rho \times g \times \mathrm{z}_{1}-\rho \times \mathrm{g} \times \mathrm{z}_{2}+ \\
\mathrm{P}_{1}-\mathrm{P}_{2}=\Delta \mathrm{E}_{\mathrm{f}}
\end{gathered}
$$

Where:

$\Delta \mathrm{E}_{\mathrm{f}}$ is the energy lost by friction of the molecules because of the viscosity. (It becomes an increase of the temperature), $\alpha_{1}$ and $\alpha_{2}$ are the coefficients of the kinetic energy in the points 1 and 2 and $\rho$ is the density of the fuel.

The potential energy between 1 and 2 is:

$$
\rho \times g \times z_{1}-\rho \times g \times z_{2}=\Delta E_{p}
$$

We note that: $\Delta \mathrm{E}_{\mathrm{p}} \approx 0$ because there are high pressures in points 1 and 2 , and the distance between 1 and 2 is very small.

We also note that: $\Delta \mathrm{E}_{\mathrm{f}} \approx 0$ because the viscosity is very small for a fuel ready to be injected, and the geometric shape between 1 and 2 is elongated which makes the most of the fuel molecules superimposed without any friction.

For the injection, we must have a thermodynamic turbulence where: $\alpha_{1}=\alpha_{2}=1$

We get consequently this equation:

$$
\rho \times \frac{V_{1}^{2}}{2 \times N^{2}}-\rho \times \frac{V_{2}^{2}}{2}+P_{1}-P_{2}=0
$$

Hence:

$V_{2}=\sqrt{\frac{2 \times P_{1}-2 \times P_{2}}{\rho}+\frac{V_{1}^{2}}{N^{2}}}=\sqrt{\frac{2}{\rho}} \times \sqrt{\frac{4 \times k \times \Delta x}{\pi \times\left(D^{2}-d^{2}\right)}-P_{2}+\frac{\rho}{2} \times \frac{V_{1}^{2}}{N^{2}}}$

We can also simplify more if the injection pump is linked to only one injector and the fuel overflow valve is not activated, with:

$$
\mathrm{q}_{\mathrm{v}}=\mathrm{S} \times \mathrm{V}=\frac{\pi \times \mathrm{d}^{2}}{4} \times \mathrm{V}_{1}
$$

We get consequently:

$$
\mathrm{V}_{1}=\frac{4 \times \mathrm{S}}{\pi \times \mathrm{d}^{2}} \times \mathrm{V}
$$

Where: $\mathrm{q}_{\mathrm{v}}$ is the volumetric flow rate of the fuel in the injection system compound of the injection pump and the injector.

We finally conclude that:

$$
\mathrm{V}_{2}=\sqrt{\frac{2}{\rho}} \times \sqrt{\frac{4 \times \mathrm{k} \times \Delta \mathrm{x}}{\pi \times\left(\mathrm{D}^{2}-\mathrm{d}^{2}\right)}-\mathrm{P}_{2}+\frac{8 \times \rho \times \mathrm{S}^{2}}{\pi^{2} \times \mathrm{d}^{4} \times \mathrm{N}^{2}} \times \mathrm{V}^{2}}
$$

A higher injection pressure enhances experimentally the spray development especially the width and a slower injection rate causes a higher peak heat release rate with a higher level of engine noise [3].

This proved formula informs us about the flow rate of the fuel at the start of the spray development. Consequently, it will allow us also to determine experimentally the shape and width of the flame in the engine cylinder for a determined type of fuel according to the properties of the 
studied engine.

Determining the shape of the flame is necessary to designate the ideal shape of the engine piston head for an improved thermal energy transformation. Consequently, it is mandatory to link theoretically all the injection process steps together by cohering my formulas with other works $[11,12,13]$ as it is mentioned before in the related works part.

A good shape allows us to improve the efficiency of the thermal energy transformation by achieving the best thrust on the engine piston, and allows also a better combustion which reduces the pollutant emissions levels [14].

For a determined fuel, the velocity $\mathrm{V}_{2}$ depends on $\mathrm{N}$ the number of the identical holes, and it increases by increasing the velocity $\mathrm{V}$ that depends directly on the engine speed.

Verification: A work from the University of Michigan [15] presents its own modeling of the injection process by using an injector similar to the one used in this paper. The modeling used formulas of different flow rates and deduced different pressures formulas, then, the authors used diagrams of the camshaft angle to compare the results of his modeling with the experiments where the number of the injector holes is $\mathrm{N}=4$.

My paper results can also be compared to the cited work where:

- The needle maximum lift $\mathrm{dx}$ stays unchanged during the injection of the same injection pump speed according to the experimental data and also to the computer model and this matches our model.

- The needle maximum lift $\mathrm{dx}$ stays approximately unchanged in the experimental data even if the injection pump speed changes and this matches our model. However, the needle maximum lift of the University of Michigan computer model changes depending on the injection pump speed.

- The maximum fuel pressure doesn't depend on v' that is fixed by the fuel rack but sometimes on the injection pump speed. When this speed is too high compared to the fuel flow rate through the injector, an instantaneous high increase of the maximum pressure happens and that may harm the injection system parts. However the camshaft injection angle increases when v' increases.

The maximum pressures of the experimental data are approximated but can also be used to verify the results given by the modeling of this paper.

\section{Conclusions and Summary}

The proper understanding of the mechanical automatic injection systems imposes a simplified modeling of the injection operation. Consequently, the required formulas of forces, pressures and energies have been exposed and proved in order to explain the injection mechanism and to discuss the efficiency variation. Many important remarks and deductions have been also presented to allow the interested audience to form a better idea about these systems maintenance operations, namely:

- The consumed injector activation energy depends exclusively on the spring characteristics.

- When the threshold pressure is surpassed, the volume taken by the fuel inside the injector increases instantaneously which causes a short delay of the injection start.

- The efficiency always decreases as the injector gets older because of the increasing setting lengths $\Delta \mathrm{x}$ and $\Delta \mathrm{x}^{\prime}$.

- The force F upon the injection pump plunger (by the camshaft) should be rigorously adjusted to reach the convenient pressure $\mathrm{P}$.

The exposed formulas can also be the basis to run computer simulations about the direct injection mechanisms in order to develop new more efficient designs of the mechanical automatic injection systems. It is also recommended to use the presented modeling with the proposed injection system parts in a simplified experiment. The experiment can use detectors to have a tabular input of the spray length and width according to specific different environments.

The future work about the internal combustion engines will be a complete energetic study of the internal combustion engines through a geometric analysis inspired by a previous short work [16] and taking the formulas of this paper into consideration.

\section{REFERENCES}

[1] Mohan, B., Yang, W., Yu, W., Tay, K. L., \& Chou, S. K. (2015). Numerical investigation on the effects of injection rate shaping on combustion and emission characteristics of biodiesel fueled CI engine. Applied Energy, 160, 737-745.

[2] Lilly, I. R. C. (1984). Diesel engine reference book.

[3] Medina, M., Fatouraie, M., \& Wooldridge, M. (2018). High-Speed Imaging Studies of Gasoline Fuel Sprays at Fuel Injection Pressures from 300 to 1500 bar (No. 2018-01-0294). SAE Technical Paper.

[4] Salvador, F. J., De la Morena, J., Bracho, G., \& Jaramillo, D. (2018). Computational investigation of diesel nozzle internal flow during the complete injection event. Journal of the Brazilian Society of Mechanical Sciences and Engineering, 40(3), 153.

[5] Hassan, M. N., Khalid, A., Mustaffa, N., Darlis, N., Jaat, N., Andsaler, A. R., \& Mohammed, A. N. (2019, January). Simulation of Biodiesel Sprays under High Ambient Temperature using Computational Fluid Dynamics. In Journal of Physics: Conference Series (Vol. 1150, No. 1, p. 012063). IOP Publishing.

[6] Abay, K., Colak, U., \& Yüksek, L. (2018). COMPUTATIONAL FLUID DYNAMICS ANALYSIS 
OF FLOW AND COMBUSTION OF A DIESEL ENGINE. Power [kw], 91, 5 .

[7] Krogerus, T., Hyvönen, M., \& Huhtala, K. (2018). Analysis of common rail pressure signal of dual-fuel large industrial engine for identification of injection duration of pilot diesel injectors. Fuel, 216, 1-9.

[8] Xu, L., Bai, X. S., Jia, M., Qian, Y., Qiao, X., \& Lu, X. (2018). Experimental and modeling study of liquid fuel injection and combustion in diesel engines with a common rail injection system. Applied energy, 230, 287-304.

[9] Arcoumanis, C., Gavaises, M., Nouri, J. M., Abdul-Wahab, E., \& Horrocks, R. W. (1998). Analysis of the flow in the nozzle of a vertical multi-hole diesel engine injector. SAE transactions, 1245-1259.

[10] Yule, A. J., \& Filipovic, I. (1992). On the break-up times and lengths of diesel sprays. International journal of heat and fluid flow, 13(2), 197-206.

[11] Patterson, M. A., \& Reitz, R. D. (1998). Modeling the effects of fuel spray characteristics on diesel engine combustion and emission. SAE transactions, 27-43.

[12] Han, Z., Xu, Z., \& Trigui, N. (2000). Spray/wall interaction models for multidimensional engine simulation. International Journal of Engine Research, 1(1), 127-146.

[13] Wang, Z., Ding, H., Ma, X., Xu, H., \& Wyszynski, M. L. (2016). Ultra-high speed imaging study of the diesel spray close to the injector tip at the initial opening stage with single injection. Applied energy, 165, 335-344.

[14] Fiore, M., Viggiano, A., Fanelli, E., Braccio, G., \& Magi, V. (2018). Influence of piston shape and injector geometry on combustion and emission characteristics of syngas in direct-injection spark-ignition engine. Energy Procedia, 148, 392-399.

[15] Wylie, E. B., Bolt, J. A., \& El-Erian, M. F. (1971). Diesel fuel injection system simulation and experimental correlation. SAE Transactions, 1855-1869.

[16] Akram, L. (2019). Moteur Alternatif Mécanique. viXra. 